\title{
REVIEW
}

\section{Clinical review: Traumatic brain injury in patients receiving antiplatelet medication}

\author{
Christopher Beynon*, Daniel N Hertle, Andreas W Unterberg and Oliver W Sakowitz
}

\begin{abstract}
As the population ages, emergency physicians are confronted with a growing number of trauma patients receiving antithrombotic and antiplatelet medication prior to injury. In cases of traumatic brain injury, pre-injury treatment with anticoagulants has been associated with an increased risk of posttraumatic intracranial haemorrhage. Since high age itself is a well-recognised risk factor in traumatic brain injury, this population is at special risk for increased morbidity and mortality. The effects of antiplatelet medication on coagulation pathways in posttraumatic intracranial haemorrhage are not well understood, but available data suggest that the use of these agents increases the risk of an unfavourable outcome, especially in cases of severe traumatic brain injury. Standard laboratory investigations are insufficient to evaluate platelet activity, but new assays for monitoring platelet activity have been developed. Commonly used interventions to restore platelet activity include platelet transfusion and application of haemostatic drugs. Nevertheless, controlled clinical trials have not been carried out and, therefore, clinical practice guidelines are not available. In addition to the risks of the acute trauma, patients are at risk for cardiac events such as life-threatening stent thrombosis if antiplatelet therapy is withdrawn. In this review article, we summarize the pathophysiologic mechanisms of the most commonly used antiplatelet agents and analyse results of studies on the effects of this treatment on patients with traumatic brain injury. Additionally, we focus on opportunities to counteract antiplatelet effects in those patients as well as on considerations regarding the withdrawal of antiplatelet therapy. In those chronically ill patients, an interdisciplinary approach involving intensivists, neurosurgeons as well as cardiologists is often mandatory.
\end{abstract}

*Correspondence: christopher.beynon@med.uni-heidelberg.de Department of Neurosurgery, Heidelberg University Hospital, Im Neuenheimer Feld 400, Heidelberg, 69120 Heidelberg, Germany

\section{Introduction}

Cardiovascular disease remains the leading cause of death in industrialized countries despite significant improvements in the therapy of acute coronary syndromes [1]. Platelets play a major role in acute coronary syndromes and are therefore a major therapeutic target. Patients on antiplatelet therapy tend to be older and are particularly prone to sustain injuries due to falls. In cases of traumatic brain injury (TBI), these patients are at increased risk since high age has been identified as a predictor of an unfavourable outcome [2]. In patients with TBI, occurrence of posttraumatic intracranial haemorrhage (ICH) may increase intracranial pressure and aggravate secondary brain damage. Therapeutic mechanisms of antiplatelet agents include inhibition of platelet aggregation, so normal haemostasis is impaired. This impairment may lead to an increased incidence of $\mathrm{ICH}$ and enlargement of haematomas in TBI, potentially increasing mortality and morbidity. Anticoagulation with vitamin $\mathrm{K}$ antagonists, such as warfarin, has been associated with a high frequency of isolated head trauma, and a high risk of death $[3,4]$. Although controlled trials have not been carried out for TBI, antagonization of preinjury vitamin $\mathrm{K}$ antagonist effects is possible through application of vitamin $\mathrm{K}$, fresh frozen plasma or prothrombin complex concentrate [5]. Especially administration of prothrombin complex concentrate allows the rapid reversal of anticoagulatory effects of vitamin $\mathrm{K}$ antagonists such as warfarin in patients with traumatic haemorrhage [6]. In cases of antiplatelet therapy, antidotes are not available since platelet enzymes are irreversibly blocked by those drugs.

In this review we analyse available studies on the impact of pre-injury use of antiplatelet agents in patients with TBI and analyse interventions for identifying and counteracting antiplatelet effects in these patients. Furthermore, we briefly review the mechanisms of action involved in antiplatelet therapy.

\section{Antiplatelet therapy}

Platelets are small, irregularly shaped anuclear subcellular fragments that are derived from megakaryocytes and play a major role in the maintenance of haemostasis. 


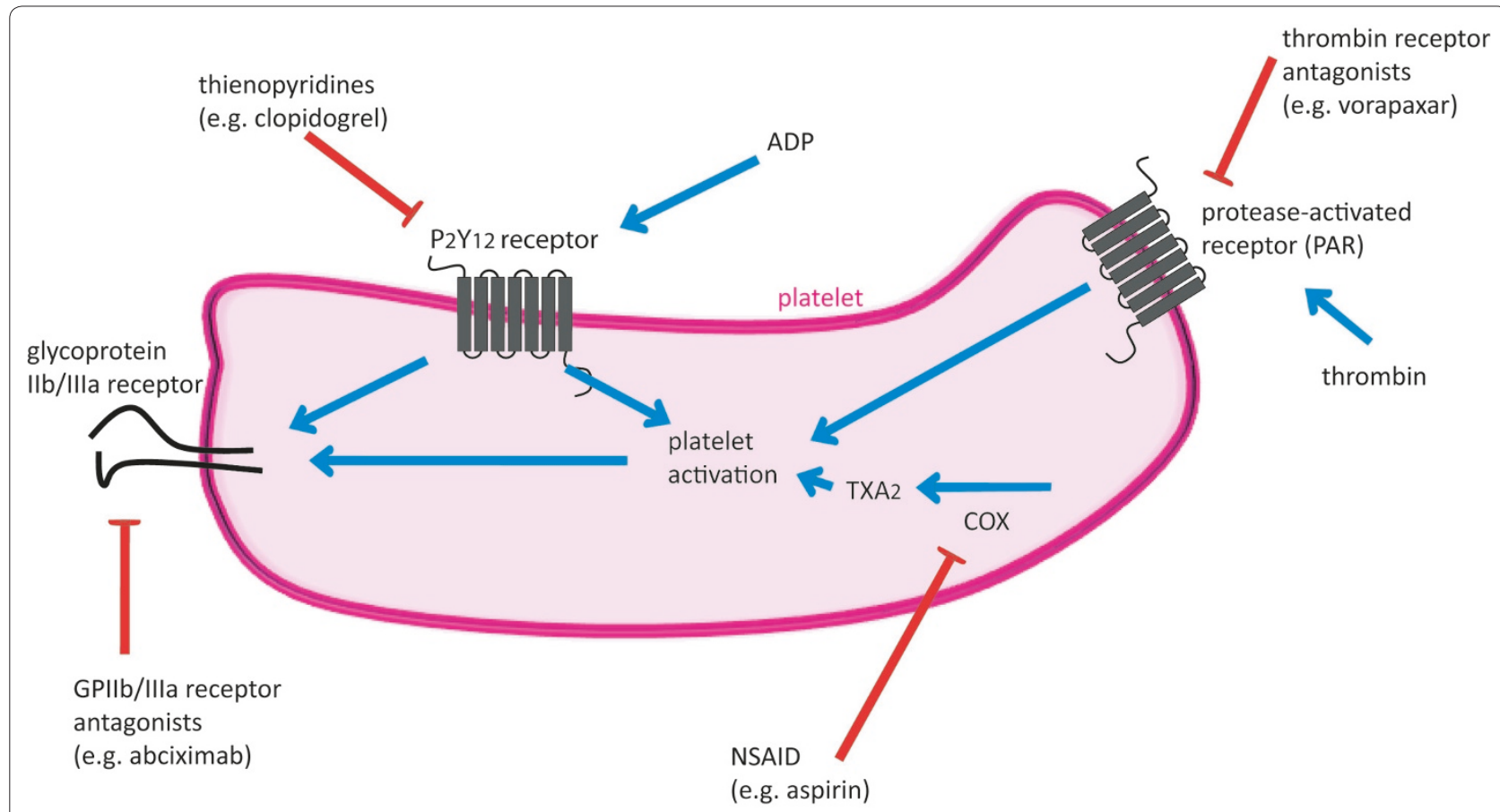

Figure 1. Schematic overview of antiplatelet medication effects on platelet pathways. COX, cyclooxygenase; NSAID, non-steroidalantinflammatory drug; TXA2, thromboxane $\mathrm{A}_{2}$.

They circulate in the blood of mammals and do not interact with endothelial cell linings of blood vessels unless stimulated by certain pathways. Damage to blood vessels results in exposure of collagen in the bloodstream and release of von Willebrandt factor from endothelial cells. Platelets are activated if they are exposed to this highly thrombogenic environment and severable soluble agonists, such as ADP, thromboxane $\mathrm{A}_{2}$, serotonin, and thrombin, recruit and activate additional platelets [7]. Platelet aggregation is mediated through glycoprotein (Gp)IIb/IIIa and the thrombus is stabilized through conversion of fibrinogen bridges to fibrin [8]. ADP signals are transduced through $\mathrm{P}_{2}$ purinergic receptors $\left(\mathrm{P}_{2} \mathrm{Y}_{1}\right.$ and $\mathrm{P}_{2} \mathrm{Y}_{12}$ ) on the surface of platelets, contributing to thrombus growth and stability. Thromboxane $\mathrm{A}_{2}$, synthesized by cyclooxygenase (COX) from arachidonic acid, amplifies platelet activation and leads to micro-vessel contraction and thrombus propagation [9]. Thrombin is an enzyme that catalyzes the cleavage of fibrinogen into soluble fibrin and is, therefore, a major mediator of the plasmatic coagulation system. It is also one of the most potent platelet activators through interaction of proteaseactivated receptors (PARs) on the platelet surface [10]. Interaction of PAR-1 and PAR-4 results in activation of platelets and smooth muscle cells and therefore contributes to platelet pro-coagulant activity and aggregation. Major pathways of platelet activation and pharmaceutical action are illustrated in Figure 1. At present, the most commonly used antiplatelet agents target $\mathrm{COX}$ and $\mathrm{P}_{2} \mathrm{Y}_{12}$ or GpIIb/IIIa receptors. Newer antiplatelet strategies, such as inhibition of thrombin receptors, are currently being investigated in clinical trials as their potential and limitations in clinical practise need to be further characterised.

\section{Non-steroidal-antinflammatory drugs}

Non-steroidal-antinflammatory drugs (NSAIDs) lead to irreversible inhibition of COX. The NSAID aspirin is the oldest and most-studied antiplatelet agent to date. Its long-term use has been shown to significantly reduce the risk of cardiovascular events and it is also commonly used for prevention of cerebral ischemic events. Since $\mathrm{COX}$ is irreversibly inhibited by aspirin, new platelets have to be generated from the bone marrow to restore platelet activity. It takes approximately 5 to 6 days to replace $50 \%$ of the circulating platelets [11].

\section{Thienopyridines}

Thienopyridines (clopidogrel, ticlopidine, prasugrel) inhibit ADP-mediated platelet activation through irreversible blockade of $\mathrm{P}_{2} \mathrm{Y}_{12}$ receptors. Long-term use of those drugs has been shown to reduce the relative risk of death, myocardial infarction and stroke after percutaneous coronary intervention by $26.9 \%$ [12]. Since ADP-mediated platelet response is irreversibly inhibited, normal platelet activity is restored after 7 days of drug withdrawal [13]. 


\section{Gpllb/IIla inhibitors}

The blockade of GpIIb/IIIa receptors represents a potent mechanism for antiplatelet activity [14]. GpIIb/IIIa inhibitors include the monoclonal antibody abciximab as well as the small-molecule antagonists eptifibatide and tirofiban. Oral application of these agents has shown no benefit with a high risk profile in clinical trials assessing their efficacy for acute coronary syndrome. Their use is therefore limited to parenteral application but they are commonly applied during intravascular procedures. The short half-time of these substances results in normal platelet activity within several hours (eptifibatide and tirofiban) to a few days (abciximab) when application is discontinued [15]. Due to their pharmacological properties and restriction to in-hospital use, GpIIb/IIIa antagonists do not play a significant role in the treatment of TBI patients.

\section{Newer antiplatelet drugs}

Despite their efficacy in the treatment of cardiovascular disease, currently available antiplatelet agents have significant side effects. Fear of anticoagulant/antiplatelet therapy-related haemorrhage is considered one of the main reasons for the gap between current guidelines for stroke prevention and clinical practice. Although it is recognised that for every $10 \%$ increase in guidelines compliance there is a $10 \%$ reduction in mortality [16], Russolillo and colleagues [17] found that there is a widespread under-use of prevention strategies. Further research in the field of antiplatelet therapy is warranted to reduce the risk of side effects such as haemorrhage. Current research activity focuses on the development of new agents of the substance classes discussed above and experimental data suggest that potential new candidates of antiplatelet targets include the effects of thrombin, serotonin, matrix metalloproteinases and CD40 ligands on platelet activity [7]. Inhibition of platelet activity through blockade of thrombin receptors has shown promising results in clinical trials [18], but the risk of bleeding complications remains a major issue. Recently published results of a multinational, randomized trial on the thrombin receptor antagonist vorapaxar in acute coronary syndromes showed no significant reduction of death from cardiovascular causes, myocardial infarction, or stroke if vorapaxar was added to standard therapy, but the risk of major bleeding, including $\mathrm{ICH}$, was significantly increased [19].

\section{Effects of pre-injury antiplatelet therapy on TBI patients}

Several authors have investigated the effects of pre-injury antiplatelet therapy in patients with TBI. Results of those studies, which have all been conducted in a retrospective fashion, are summarized in Table 1. In two studies, posttraumatic $\mathrm{ICH}$ was associated with a significantly increased mortality rate in patients on antiplatelet therapy when compared to historical controls [20,21]. These findings are supported by a study by Major and colleagues [22], who found evidence that posttraumatic $\mathrm{ICH}$ is associated with a mortality rate of $21 \%$ in patients on antiplatelet therapy. In contrast, no increased risk of mortality was observed in all TBI patients on antiplatelet therapy. The study was designed to evaluate all patients with head injuries admitted to an emergency department, suggesting a high rate of patients with a mild to moderate TBI. A study by Spektor and colleagues [23] revealed no higher incidence of posttraumatic $\mathrm{ICH}$ in patients treated with low-dose aspirin. Since analysis was restricted to mild and moderate TBI, it is unclear whether these findings also apply to severe TBI. Jones and colleagues [24] showed that patients with pre-injury clopidogrel treatment had higher rates of neurosurgical interventions as well as more episodes of rebleeding and a higher need of transfusion of blood products. These findings are supported by Wong and colleagues [25], who found that patients on clopidogrel therapy were more likely to be discharged to long-term inpatient facilities. Although outcome was not analysed in this study, the results suggest that pre-injury use of clopidogrel may increase the risk of an unfavourable outcome after TBI. Bonville and colleagues [26] analysed the outcome of trauma patients who were anticoagulated with warfarin or antiplatelet agents. In this study, only warfarin was associated with an increased risk of posttraumatic ICH and death. Antiplatelet therapy with aspirin and clopidogrel did not increase rate of mortality and did not affect length of hospital stay. Bachelani and colleagues [27] found that neither history of aspirin intake nor platelet inhibition measured by a specific assay was associated with an increased risk of progression of $\mathrm{ICH}$, craniotomy, mortality or poor outcome. In contrast to these findings, Fabbri and colleagues [28] showed that pre-injury use of aspirin and indobufen (a NSAID) was associated with an increased risk of posttraumatic intracranial lesions in 14,288 patients with mild TBI. The results of those studies are conflicting and do not allow a comprehensive characterisation of antiplatelet agent effects on patients with TBI.

Several factors may have contributed to the discordancy of the results of cited studies. Importantly, the retrospective design and small sample sizes are major deficits of those studies and result in limited significance of reported findings. Additionally, in all studies assessment of pre-injury use of antiplatelet agents was based on the patient's history and not on assessment of platelet activity through laboratory examinations. Incompliance of patients regarding the intake of prescribed drugs as well as ineffectiveness of antiplatelet agents in some 
Table 1. Overview of retrospective studies on the effects of antiplatelet medication in patients with traumatic brain injury

\begin{tabular}{|c|c|c|c|c|c|}
\hline Study & Inclusion criteria & Antiplatelet therapy & $\begin{array}{l}\text { Number } \\
\text { of subjects }\end{array}$ & Mortality rate & Major findings \\
\hline $\begin{array}{l}\text { Mina et al. } \\
2002[20]\end{array}$ & Posttraumatic ICH & Aspirin & 19 & $\begin{array}{l}47 \% \text { aspirin group; } \\
8 \% \text { control group }\end{array}$ & $\begin{array}{l}\text { Mortality significantly increased with aspirin } \\
\text { therapy. No difference in mortality rates between } \\
\text { aspirin and warfarin treated patients }\end{array}$ \\
\hline $\begin{array}{l}\text { Spektor et al. } \\
2003[23]\end{array}$ & $\begin{array}{l}\text { Mild and moderate } \\
\text { TBl, age }>60 \text { years }\end{array}$ & Aspirin (100 mg/day) & 110 & NR & $\begin{array}{l}\text { Aspirin therapy had no effect on incidence of } \\
\text { posttraumatic ICH after mild to moderate TBI }\end{array}$ \\
\hline $\begin{array}{l}\text { Ohm et al. } \\
2005 \text { [21] }\end{array}$ & Posttraumatic ICH & Aspirin, clopidogrel & 90 & $\begin{array}{l}23 \% \text { antiplatelet group; } \\
8 \% \text { control group }\end{array}$ & $\begin{array}{l}\text { Mortality threefold increased with antiplatelet } \\
\text { therapy. GCS }<12 \text { and age }>76 \text { years risk factors for } \\
\text { death in patients on antiplatelet therapy }\end{array}$ \\
\hline $\begin{array}{l}\text { Jones et al. } \\
2006[24]\end{array}$ & All TBI, age $>50$ years & Clopidogrel & 43 & $7 \%$ clopidogrel group & $\begin{array}{l}\text { Clopidogrel-treated patients have higher rates of } \\
\text { cranial surgery and episodes of rebleeds. More } \\
\text { blood products were transfused in clopidogrel- } \\
\text { treated patients }\end{array}$ \\
\hline $\begin{array}{l}\text { Wong et al. } \\
2008 \text { [25] }\end{array}$ & All TB| & Aspirin, clopidogrel & 111 & $\begin{array}{l}14 \% \text { clopidogrel group; } \\
3 \% \text { aspirin group }\end{array}$ & $\begin{array}{l}\text { Clopidogrel-treated patients were more likely to } \\
\text { be discharged to long-term inpatient facilities }\end{array}$ \\
\hline $\begin{array}{l}\text { Major et al. } \\
2009[22]\end{array}$ & All TBI & Aspirin, clopidogrel & 287 & $1.4 \%$ aspirin group & $\begin{array}{l}\text { Mortality rate } 21 \% \text { in patients on aspirin with } \\
\text { posttraumatic } \mathrm{ICH} \text {. Three of the four patients } \\
\text { who died in the aspirin group deteriorated with a } \\
\text { significant delay }\end{array}$ \\
\hline $\begin{array}{l}\text { Bonville et al. } \\
2011[26]\end{array}$ & All TBI & Aspirin, clopidogrel & 271 & $\begin{array}{l}12.3 \% \text { aspirin group; } \\
9.3 \% \text { clopidogrel group }\end{array}$ & $\begin{array}{l}\text { Use of antiplatelet agents did not affect mortality } \\
\text { or length of hospital stay }\end{array}$ \\
\hline
\end{tabular}

GCS, Glasgow Coma Scale; ICH, intracranial haemorrhage; TBI, traumatic brain injury.

patients may have led to different degrees of platelet activity inhibition in the different study populations. Detection of posttraumatic $\mathrm{ICH}$ and enlargement of intracranial lesions was not performed in a standardized manner, and as several factors have a crucial impact on these findings, such as timing of computed tomography scans, comparison of the results has only limited validity. Finally, the mechanisms of injury and severity of injuries differ substantially between reported studies. While some studies were restricted to 'isolated' head injury, others included patients with relevant injuries to other organ systems, such as liver laceration and pulmonary contusions. In the context of polytrauma, attribution of parameters like mortality to TBI or other injuries can be difficult and this also may explain differences between the results.

In conclusion, despite the deficits of reported studies, the available data suggest that patients on antiplatelet therapy may have a higher risk of mortality and morbidity after TBI, especially in cases of posttraumatic ICH. Although risk factors have not been identified yet, it seems that patients with more severe TBI might be at particular risk of negative effects due to pre-injury antiplatelet therapy. Nevertheless, well-designed studies are desperately needed to shed light on this important topic. Important factors such as degree of platelet activity inhibition and the impact of antiplatelet medication on neurologic long-term outcome after TBI have to be taken into consideration when conducting the design of prospective studies.

\section{Diagnostic evaluation of antiplatelet therapy in TBI patients}

Standard laboratory coagulation tests in TBI patients include assessment of activated partial thromboplastin time, prothrombin time, fibrinogen, and platelet count. These laboratory values do not allow assessment of platelet activity. History regarding the use of antiplatelet therapy should be evaluated in all TBI patients, although this may not be possible in all cases. Thrombelastometry is a method allowing for haemostasis testing, including platelet activity, in whole blood [29]. Its use has been suggested for the management of active haemorrhage in trauma victims to guide haemostatic therapy [30] and a recent study showed its results to be predictive of outcome in patients with severe TBI [31]. Further research will show if the use of this tool is of benefit in patients with TBI, especially if disorders of the coagulatory system are apparent. Bachelani and colleagues [27] used the specific assay 'Aspirin Response Test' (VerifyNow ${ }^{\odot}$, Accumetrics, San Diego, CA, USA) for identifying effects of aspirin on platelet activity after TBI. Originally, this test was developed for cardiologists to assess the efficacy of aspirin-induced platelet inhibition 
and monitor patient compliance. In this study, this test showed that $42 \%$ of patients with unknown history of aspirin had signs of platelet inhibition. The authors assessed the efficacy of platelet transfusion through repeating the 'Aspirin Response Test' and, interestingly, failure of normalizing platelet function was associated with a trend towards a higher risk of mortality. A specific point-of-care assay for detection of clopidogrel-induced platelet inhibition (VerifyNow ${ }^{\oplus}-\mathrm{P} 2 \mathrm{Y} 12$, Accumetrics) is also available. Bansal and colleagues [32] used this assay in 46 trauma patients and showed that a large percentage of patients had undetectable or low platelet inhibition despite reported use of clopidogrel. Incompliance of patients as well as ineffectiveness of clopidogrel in some patients (so-called 'nonresponders') were discussed by the authors as causes of this discrepancy. Assay information may present valuable information in the clinical setting, since unnecessary interventions such as platelet transfusion or application of haemostatic drugs can be avoided. The role of specific test assays in the management of TBI patients has to be further evaluated before routine use can be recommended.

\section{Counteracting effects of antiplatelet therapy}

The use of anticoagulant agents has increased in the past and is expected to continue to increase. It is surprising, therefore, that there is a paucity of evidence regarding the management of TBI in anticoagulated patients. Since controlled trials and guidelines for the treatment of TBI patients with pre-injury anticoagulant use are lacking, management of these patients often relies on empiric evaluation and personal experience. Therapeutic regimens differ not only between different trauma centres but also between different surgeons and physicians. Several approaches have been reported in the literature. Of these, some are based on pathophysiologic rationales and some have been adopted from other fields of medicine.

\section{Transfusion of platelets}

Antiplatelet therapy with NSAIDs and thienopyridines leads to an irreversible blockade of important enzymatic pathways of platelet activation. The pathophysiologic rationale of platelet transfusion is to deliver platelets with normal enzymatic levels to allow platelet activation and aggregation. A study on healthy individuals treated with clopidogrel showed that transfusion of 10 platelet concentrate units reverses clopidogrel-induced platelet disaggregation ex vivo [33]. A study on patients with spontaneous $\mathrm{ICH}$ receiving antiplatelet agents showed no reduction of the frequency of hematoma expansion through platelet transfusion [34], but early transfusion of platelets within 12 hours of ictus resulted in improved platelet activity assays as well as smaller final haemorrhage size and more independence at 3 months [35].
Downey and colleagues retrospectively analysed patients on antiplatelet medication at their institution who underwent platelet transfusion $(n=166)$ to those patients on antiplatelet medication who did not $(n=162)$ [36]. No differences regarding mortality were observed between both groups. A further study by Washington and colleagues [37] on 113 patients with mild TBI and preinjury antiplatelet therapy showed that platelet transfusion had no impact on rate of $\mathrm{ICH}$ progression, neurological decline or neurological outcome at hospital discharge. In this study, transfusion of any type (platelets, fresh frozen plasma, or blood) was a strong predictor of medical decline. Platelet transfusion is associated with several adverse effects, such as infectious and immunological complications [38]. Additionally, platelets have to be acquired from healthy donors, have a limited availability and transfusions are also a considerable economic factor. In light of available data of studies, routine platelet transfusion cannot be recommended in TBI patients with pre-injury antiplatelet therapy and further trials clarifying this issue are needed.

\section{Desmopressin}

Desmopressin is a widely used haemostatic drug in patients with bleeding disorders such as haemophilia, von Willebrandt's disease and various platelet disorders. The substance can be effective in reducing bleeding risks through releasing factor VIII and von Willebrandt factor from endogenous reservoirs as well as increasing platelet adhesiveness [39]. Due to possible thromboembolic side effects, routine use in bleeding trauma victims is not recommended [30]. Nevertheless, the potential of this substance to (partially) reverse activity of antiplatelet medication is well-recognized [40,41]. A study on healthy volunteers showed that after oral administration of $375 \mathrm{mg}$ clopidogrel, nasal application of $300 \mu \mathrm{g}$ desmopressin increased ristocetin cofactor and platelet activity, thus improving primary haemostasis [42]. In patients treated with aspirin undergoing elective cholecystectomy, desmopressin normalized in vivo bleeding time [43] and it also reduced postoperative haemorrhage in aspirintreated patients receiving coronary artery bypass operations [44]. Additionally, a case report on a patient undergoing emergency carotid endarterectomy showed that desmopressin led to partial reversal of clopidogrel- and aspirin-induced effects on platelets as assessed by thrombelastography [45]. Clinical studies on the use of this substance in TBI patients receiving antiplatelet medication have not been carried out yet, but in light of these reports, the application of desmopressin should be considered, especially if a strong bleeding tendency is apparent. The recommended dosage for intravenous application of desmopressin is $0.3 \mu \mathrm{g} / \mathrm{kg}$ body weight with repetitive application after 8 to 12 hours if necessary [39]. 


\section{Recombinant factor VIla}

Recombinant factor VII (FVIIa) is a haemostatic agent used in various bleeding disorders, such as haemophilia A and B [46]. Several mechanisms of action have been identified where FVIIa significantly increases thrombin levels. The drug was evaluated in the therapy of spontaneous $\mathrm{ICH}$, but its application did not improve survival or functional outcome, despite reducing haematoma growth [47]. Dutton and colleagues [48] retrospectively analysed 81 trauma patients with coagulopathy and active haemorrhage. In most cases, application of FVIIa resulted in an immediate reduction in coagulopathic haemorrhage. Narayan and colleagues [49] reported a trend towards reduced haematoma growth as well as a trend towards increased incidence of asymptomatic deep vein thrombosis after application of FVIIa in 61 patients with posttraumatic ICH. It is well recognized that FVIIa also has direct effects on platelets, increasing their adhesion and aggregation through FVIIa-mediated thrombin formation [50,51]. It has been used in patients with thrombopaenia due to haematologic malignancies [52], but a recent experimental study showed no effects on bleeding time after application of FVIIa in aspirinand clopidogrel-treated rabbits [53]. Nevertheless, application of FVIIa $(20 \mu \mathrm{g} / \mathrm{kg}$ body weight $)$ reversed the effects of clopidogrel on blood loss in healthy individuals undergoing an experimentally induced punch biopsy [54]. Further research is warranted to define the role of FVIIa in the reversal of antiplatelet therapy effects in TBI.

\section{Tranexamic acid}

Tranexamic acid (TXA) is an antifibrinolytic drug blocking the lysine binding site of the plasminogen molecule and therefore inhibiting its access to fibrin molecules. It has been widely used in cardiac surgery to reduce intraoperative blood loss [55] and the recent multicentre trial CRASH-2 proved TXA to safely reduce the risk of death in bleeding trauma victims [56]. Although the drug's primary mechanism of action is counteracting hyperfibrinolysis, direct effects on the platelet system have been reported. Application of the drug partially reversed platelet aggregation dysfunction in patients on aspirin and clopidogrel undergoing elective cardiac surgery [57]. Results of a study by Pleym and colleagues [58] on patients treated with aspirin and undergoing cardiopulmonary bypass surgery showed that a single dose of TXA (30 mg/kg body weight) resulted in a significant reduction of postoperative bleeding. Effects of antifibrinolytic drugs on $\mathrm{ICH}$ and brain metabolism are largely unknown. The use of TXA in patients with unsecured ruptured cerebral aneurysms reduces the risk of re-bleeding, but this benefit is offset by an increased risk for cerebral ischaemia, finally leading to an increased risk of poor outcome [59]. Nevertheless, a subgroup analysis of the CRASH-2 data did not show any beneficial nor harmful effects of TXA in TBI patients [60], so further clinical trials should be carried out to evaluate this therapeutic approach in this population.

\section{Withdrawal of antiplatelet therapy after TBI}

The most critical period regarding enlargement of posttraumatic ICH after TBI is the acute phase after trauma. A prospective observational study revealed that posttraumatic ICH enlarges in more than half of TBI patients within the first 24 hours after trauma [61]. Exacerbation of $\mathrm{ICH}$ due to impaired platelet activity is therefore most likely to occur in this phase and withdrawal of antiplatelet therapy should be considered in respective patients. In addition to the risks associated with TBI, patients may also be at high risk if antiplatelet therapy is withdrawn. After stent implantation due to coronary heart disease, the risk of life-threatening stent thrombosis is increased 30 -fold if clopidogrel therapy is discontinued within the first 30 days [62]. Discontinuation of clopidogrel within the first 6 months, but not after 6 months, is an independent determinant of stent thrombosis [63]. A meta-analysis of 50,279 patients for secondary prevention for coronary artery disease revealed that the cardiac complication rate is threefold increased after aspirin withdrawal [64]. Withdrawal of antiplatelet medication in patients in need of surgery is an issue that is widely discussed and clinical recommendations have been published recently $[65,66]$. For this setting, it has been shown that the risk of coronary thrombosis after withdrawal of antiplatelet medication is greater than the risk of surgical bleeding if antiplatelet medication is continued [67]. Nevertheless, it is well-recognized that bleeding in closed spaces, such as in $\mathrm{ICH}$, may result in fatal consequences and the cited guidelines recommend that, in cases of intracranial surgical interventions, discontinuation of aspirin and/or clopidogrel prior to the procedure should be considered. 'Bridging therapy' with tirofiban after withdrawal of clopidogrel showed good safety and efficacy profiles in patients with recently implanted cardiac stents undergoing urgent surgical procedures [68], but GPIIa/IIIb receptor antagonists themselves may cause enlargement of posttraumatic ICH in TBI patients. 'Bridging therapy' with heparin was ineffective in reducing cardiac events after withdrawal of antiplatelet therapy in patients with cardiac stents [69]. In a study on 1,236 patients hospitalized for acute coronary events, in $4.1 \%$ of cases the event was due to withdrawal of antiplatelet therapy and occurred with a mean delay of $10 \pm 1.9$ days [70]. Whether to withdraw antiplatelet therapy in TBI patients or reinitiate it after it was withdrawn are decisions that depend on a variety of circumstances, such as the evidence and extent of $\mathrm{ICH}$ and also the indication for pre-injury use of antiplatelet agents. Each approach 
should be tailored to be patient-specific and discussions should involve treating neurosurgeons and intensivists as well as cardiologists. Decisions should be re-evaluated on a regular basis, depending on the patient's clinical course.

\section{Conclusion}

The use of antiplatelet agents in patients will increase as the population ages and because cardiovascular diseases have one of the highest incidence rates of all diseases in industrialized countries. TBI plays a major economic role in society since survivors often suffer serious neurologic sequelae resulting in high dependency. Available data from studies suggest that the pre-injury use of antiplatelet agents yields risks for TBI patients that may lead to an unfavourable outcome. Options to (partially) restore platelet activity include transfusion of platelets and application of haemostatic drugs such as desmopressin, TXA and FVIIa. Guidelines regarding their use are missing since these agents have not been subject to controlled trials in TBI so far. Withdrawal of antiplatelet agents may carry high risks for patients, so treatment has to consider comorbidities and an interdisciplinary approach should be chosen. Further trials are needed to characterise the impact of pre-injury antiplatelet therapy on TBI victims and to establish protocols optimizing treatment modalities for those patients.

\section{Abbreviations}

COX, cyclooxygenase; FVIla, factor VIla; Gp, glycoprotein; ICH, intracranial haemorrhage; NSAID, non-steroidal-antinflammatory drug; PAR, proteaseactivated receptor; $T B I$, traumatic brain injury; TXA, tranexamic acid.

\section{Competing interests}

The authors declare that they have no competing interests.

Published: 26 July 2012

References

1. Lopes RD: Antiplatelet agents in cardiovascular disease. J Thromb Thrombolysis 2011, 31:306-309.

2. Moppett IK: Traumatic brain injury: assessment, resuscitation and early management. Br J Anaesth 2007, 99:18-31.

3. Karni A, Holtzman R, Bass T, Zorman G, Carter L, Rodriguez L, BennettShipman VJ, Lottenberg L: Traumatic head injury in the anticoagulated elderly patient: a lethal combination. Am Surg 2001, 67:1098-1100.

4. Lavoie A, Ratte S, Clas D, Demers J, Moore L, Martin M, Bergeron E: Preinjury warfarin use among elderly patients with closed head injuries in a trauma center. J Trauma 2004, 56:802-807.

5. Vang ML, Hvas AM, Ravn HB: Urgent reversal of vitamin $\mathrm{K}$ antagonist therapy. Acta Anaesthesiol Scand 2011, 55:507-516.

6. Chapman SA, Irwin ED, Beal AL, Kulinski NM, Hutson KE, Thorson MAL: Prothrombin complex concentrate versus standard therapies for INR reversal in trauma patients receiving warfarin. Ann Pharmacother 2011, 45:869-875

7. Minno MNDD, Guida A, Camera M, Colli S, Minno GD, Tremoli E: Overcoming limitations of current antiplatelet drugs: a concerted effort for more profitable strategies of intervention. Ann Med 2011, 43:531-544.

8. Varga-Szabo D, Pleines I, Nieswandt B: Cell adhesion mechanisms in platelets. Arterioscler Thromb Vasc Biol 2008, 28:403-412.

9. Raymenants E, Yang B, Nicolini F, Behrens P, Lawson D, Mehta JL: Verapamil and aspirin modulate platelet-mediated vasomotion in arterial segments with intact or disrupted endothelium. J Am Coll Cardiol 1993, 22:684-689.

10. De Meyer SF, Vanhoorelbeke K, Broos K, Salles II, Deckmyn H: Antiplatelet drugs. Br J Haematol 2008, 142:515-528.

11. Powner DJ, Hartwell EA, Hoots WK: Counteracting the effects of anticoagulants and antiplatelet agents during neurosurgical emergencies. Neurosurgery 2005, 57:823-831; discussion 823-831.

12. Steinhubl SR, Berger PB, Mann JT 3rd, Fry ETA, DeLago A, Wilmer C, Topol EJ: Early and sustained dual oral antiplatelet therapy following percutaneous coronary intervention: a randomized controlled trial. JAMA 2002, 288:2411-2420.

13. Weber AA, Braun M, Hohlfeld T, Schwippert B, Tschöpe D, Schrör K: Recovery of platelet function after discontinuation of clopidogrel treatment in healthy volunteers. Br J Clin Pharmacol 2001, 52:333-336.

14. Aragam KG, Bhatt DL: Antiplatelet therapy in acute coronary syndromes. J Cardiovasc Pharmacol Ther 2011, 16:24-42.

15. Scarborough RM, Kleiman NS, Phillips DR: Platelet glycoprotein IIb/llla antagonists. What are the relevant issues concerning their pharmacology and clinical use? Circulation 1999, 100:437-444.

16. Peterson ED, Roe MT, Mulgund J, DeLong ER, Lytle BL, Brindis RG, Smith SC Jr, Pollack CV Jr, Newby LK, Harrington RA, Gibler WB, Ohman EM: Association between hospital process performance and outcomes among patients with acute coronary syndromes. JAMA 2006, 295:1912-1920.

17. Russolillo A, Di Minno MND, Tufano A, Prisco D, Di Minno G: Filling the gap between science $\&$ clinical practice: prevention of stroke recurrence. Thromb Res 2012, 129:3-8.

18. Tello-Montoliu A, Tomasello SD, Ueno M, Angiolillo DJ: Antiplatelet therapy: thrombin receptor antagonists. Br J Clin Pharmacol 2011, 72:658-671.

19. Tricoci P, Huang Z, Held C, Moliterno DJ, Armstrong PW, Van de Werf F, White HD, Aylward PE, Wallentin L, Chen E, Lokhnygina Y, Pei J, Leonardi S, Rorick TL, Kilian AM, Jennings LHK, Ambrosio G, Bode C, Cequier A, Cornel JH, Diaz R, Erkan A, Huber K, Hudson MP, Jiang L, Jukema JW, Lewis BS, Lincoff AM, Montalescot G, Nicolau JC, et al:: Thrombin-receptor antagonist vorapaxar in acute coronary syndromes. N Engl J Med 2012, 366:20-33.

20. Mina AA, Knipfer JF, Park DY, Bair HA, Howells GA, Bendick PJ: Intracranial complications of preinjury anticoagulation in trauma patients with head injury. J Trauma 2002, 53:668-672.

21. Ohm C, Mina A, Howells G, Bair H, Bendick P: Effects of antiplatelet agents on outcomes for elderly patients with traumatic intracranial hemorrhage. J Trauma 2005, 58:518-522.

22. Major J, Reed MJ: A retrospective review of patients with head injury with coexistent anticoagulant and antiplatelet use admitted from a UK emergency department. Emerg Med J 2009, 26:871-876.

23. Spektor S, Agus S, Merkin V, Constantini S: Low-dose aspirin prophylaxis and risk of intracranial hemorrhage in patients older than 60 years of age with mild or moderate head injury: a prospective study. J Neurosurg 2003, 99:661-665.

24. Jones K, Sharp C, Mangram AJ, Dunn EL: The effects of preinjury clopidogrel use on older trauma patients with head injuries. Am J Surg 2006, 192:743-745.

25. Wong DK, Lurie F, Wong $L L$ : The effects of clopidogrel on elderly traumatic brain injured patients. J Trauma 2008, 65:1303-1308.

26. Bonville DJ, Ata A, Jahraus CB, Arnold-Lloyd T, Salem L, Rosati C, Stain SC: Impact of preinjury warfarin and antiplatelet agents on outcomes of trauma patients. Surgery 2011, 150:861-868.

27. Bachelani AM, Bautz JT, Sperry UL, Corcos A, Zenati M, Billiar TR, Peitzman AB, Marshall GT: Assessment of platelet transfusion for reversal of aspirin after traumatic brain injury. Surgery 2011, 150:836-843.

28. Fabbri A, Servadei F, Marchesini G, Stein SC, Vandelli A: Predicting intracranial lesions by antiplatelet agents in subjects with mild head injury. J Neurol Neurosurg Psychiatr 2010, 81:1275-1279.

29. Chen A, Teruya J: Global hemostasis testing thromboelastography: old technology, new applications. Clin Lab Med 2009, 29:391-407.

30. Rossaint R, Bouillon B, Cerny V, Coats TJ, Duranteau J, Fernández-Mondéjar E, Hunt BJ, Komadina R, Nardi G, Neugebauer E, Ozier Y, Riddez L, Schultz A, Stahel PF, Vincent J-L, Spahn DR: Management of bleeding following major trauma: an updated European quideline. Crit Care 2010, 14:R52.

31. Schöchl H, Solomon C, Traintinger S, Nienaber U, Tacacs-Tolnai A, Windhofer C, Bahrami S, Voelckel W: Thromboelastometric (ROTEM) findings in patients suffering from isolated severe traumatic brain injury. $J$ Neurotrauma 2011, 28:2033-2041.

32. Bansal V, Fortlage D, Lee J, Doucet J, Potenza B, Coimbra R: A new clopidogrel (Plavix) point-of-care assay: rapid determination of antiplatelet activity in trauma patients. J Trauma 2011 10:65-69; discussion 69-70. 
33. Vilahur G, Choi BG, Zafar MU, Viles-Gonzalez JF, Vorchheimer DA, Fuster V, Badimon JJ: Normalization of platelet reactivity in clopidogrel-treated subjects. J Thromb Haemost 2007, 5:82-90.

34. Ducruet AF, Hickman ZL, Zacharia BE, Grobelny BT, DeRosa PA, Landes E, Lei S, Khandji J, Gutbrod S, Connolly ES Jr: Impact of platelet transfusion on hematoma expansion in patients receiving antiplatelet agents before intracerebral hemorrhage. Neurol Res 2010, 32:706-710.

35. Naidech AM, Liebling SM, Rosenberg NF, Lindholm PF, Bernstein RA, Batjer $\mathrm{HH}$, Alberts MJ, Kwaan HC: Early platelet transfusion improves platelet activity and may improve outcomes after intracerebral hemorrhage. Neurocrit Care 2011, 16:82-87.

36. Downey DM, Monson B, Butler KL, Fortuna GR Jr, Saxe JM, Dolan JP, Markert RJ, McCarthy MC: Does platelet administration affect mortality in elderly head-injured patients taking antiplatelet medications? Am Surg 2009, 75:1100-1103.

37. Washington CW, Schuerer DJE, Grubb RL Jr: Platelet transfusion: an unnecessary risk for mild traumatic brain injury patients on antiplatelet therapy. J Trauma 2011, 71:358-363.

38. Norfolk DR, Ancliffe PJ, Contreras M, Hunt BJ, Machin SJ, Murphy WG, Williamson LM: Consensus Conference on Platelet Transfusion, Royal College of Physicians of Edinburgh, 27-28 November 1997. Synopsis of background papers. Br J Haematol 1998, 101:609-617.

39. Lethagen S: Desmopressin (DDAVP) and hemostasis. Ann Hematol 1994, 69:173-180.

40. Levi M, Eerenberg E, Kamphuisen PW: Bleeding risk and reversal strategies for old and new anticoagulants and antiplatelet agents. J Thromb Haemost 2011, 9:1705-1712

41. Beshay JE, Morgan H, Madden C, Yu W, Sarode R: Emergency reversal of anticoagulation and antiplatelet therapies in neurosurgical patients. J Neurosurg 2010, 112:307-318.

42. Leithäuser B, Zielske D, Seyfert UT, Jung F: Effects of desmopressin on platelet membrane glycoproteins and platelet aggregation in volunteers on clopidogrel. Clin Hemorheol Microcirc 2008, 39:293-302.

43. Flordal PA, Sahlin S: Use of desmopressin to prevent bleeding complications in patients treated with aspirin. Br J Surg 1993, 80:723-724.

44. Gratz I, Koehler J, Olsen D, Afshar M, DeCastro N, Spagna PM, Ablaza SG, Larijani GE: The effect of desmopressin acetate on postoperative hemorrhage in patients receiving aspirin therapy before coronary artery bypass operations. J Thorac Cardiovasc Surg 1992, 104:1417-1422.

45. Ranucci M, Nano G, Pazzaglia A, Bianchi P, Casana R, Tealdi DG: Platelet mapping and desmopressin reversal of platelet inhibition during emergency carotid endarterectomy. J Cardiothorac Vasc Anesth 2007. 21:851-854

46. Roberts HR, Monroe DM, White GC: The use of recombinant factor VIla in the treatment of bleeding disorders. Blood 2004, 104:3858-3864.

47. Mayer SA, Brun NC, Begtrup K, Broderick J, Davis S, Diringer MN, Skolnick BE, Steiner T: Efficacy and safety of recombinant activated factor VII for acute intracerebral hemorrhage. N Engl J Med 2008, 358:2127-2137.

48. Dutton RP, McCunn M, Hyder M, D'Angelo M, O'Connor J, Hess JR, Scalea TM: Factor VIla for correction of traumatic coagulopathy. J Trauma 2004, 57:709-718; discussion 718-719.

49. Narayan RK, Maas AIR, Marshall LF, Servadei F, Skolnick BE, Tillinger MN: Recombinant factor VIIA in traumatic intracerebral hemorrhage: results of a dose-escalation clinical trial. Neurosurgery 2008, 62:776-786; discussion 786-788.

50. Altman R, Scazziota A, DE Lourdes Herrera M, Gonzalez C: Recombinant factor VIla reverses the inhibitory effect of aspirin or aspirin plus clopidogrel on in vitro thrombin generation. J Thromb Haemost 2006 4:2022-2027.

51. Lisman T, Adelmeijer J, Cauwenberghs S, Van Pampus ECM, Heemskerk JWM, De Groot PG: Recombinant factor VIla enhances platelet adhesion and activation under flow conditions at normal and reduced platelet count. J Thromb Haemost 2005, 3:742-751.

52. De Fabritiis P, Dentamaro T, Picardi A, Cudillo L, Masi M, Amadori S: Recombinant factor VIla for the management of severe hemorrhages in patients with hematologic malignancies. Haematologica 2004, 89:243-245.

53. Hindy-François C, Bachelot-Loza C, Le Bonniec B, Grelac F, Dizier B, Godier A, Emmerich J, Gaussem P, Samama C-M: Recombinant activated factor VII does not reduce bleeding in rabbits treated with aspirin and clopidogrel. Thromb Haemost 2010, 104:823-830.

54. Skolnick BE, Shenouda M, Khutoryansky NM, Pusateri AE, Gabriel D, Carr ME:
Reversal of clopidogrel-induced bleeding with rFVIla in healthy subjects: a randomized, placebo-controlled, double-blind, exploratory study. Anesth Analg 2011, 113:703-710

55. Dunn CJ, Goa KL: Tranexamic acid: a review of its use in surgery and other indications. Drugs 1999, 57:1005-1032.

56. Shakur H, Roberts I, Bautista R, Caballero J, Coats T, Dewan Y, El-Sayed H, Gogichaishvili T, Gupta S, Herrera J, Hunt B, Iribhogbe P, Izurieta M, Khamis H, Komolafe E, Marrero M-A, Mejía-Mantilla J, Miranda J, Morales C, Olaomi O, Olldashi F, Perel P, Peto R, Ramana PV, Ravi RR, Yutthakasemsunt S: Effects of tranexamic acid on death, vascular occlusive events, and blood transfusion in trauma patients with significant haemorrhage (CRASH-2): a randomised, placebo-controlled trial. Lancet 2010, 376:23-32.

57. Weber CF, Görlinger K, Byhahn C, Moritz A, Hanke AA, Zacharowski K, Meininger D: Tranexamic acid partially improves platelet function in patients treated with dual antiplatelet therapy. Eur J Anaesthesiol 2011, 28:57-62.

58. Pleym H, Stenseth R, Wahba A, Bjella L, Karevold A, Dale O: Single-dose tranexamic acid reduces postoperative bleeding after coronary surgery in patients treated with aspirin until surgery. Anesth Analg 2003, 96:923-928, table of contents.

59. Roos YBWEM, Rinkel GJE, Vermeulen M, Algra A, van Gijn J: Antifibrinolytic therapy for aneurysmal subarachnoid haemorrhage. Cochrane Database Syst Rev 2003:CD001245.

60. Effect of tranexamic acid in traumatic brain injury: a nested randomised, placebo controlled trial (CRASH-2 Intracranial Bleeding Study). BMJ 2011, 343:d3795.

61. Narayan RK, Maas AIR, Servadei F, Skolnick BE, Tillinger MN, Marshall LF: Progression of traumatic intracerebral hemorrhage: a prospective observational study. J Neurotrauma 2008, 25:629-639.

62. Moussa ID, Colombo A: Antiplatelet therapy discontinuation following drug-eluting stent placement: dangers, reasons, and management recommendations. Catheter Cardiovasc Interv 2009, 74:1047-1054.

63. Airoldi F, Colombo A, Morici N, Latib A, Cosgrave J, Buellesfeld L, Bonizzoni E, Carlino M, Gerckens U, Godino C, Melzi G, Michev I, Montorfano M, Sangiorg GM, Qasim A, Chieffo A, Briguori C, Grube E: Incidence and predictors of drug-eluting stent thrombosis during and after discontinuation of thienopyridine treatment. Circulation 2007, 116:745-754.

64. Biondi-Zoccai GGL, Lotrionte M, Agostoni P, Abbate A, Fusaro M, Burzotta F, Testa L, Sheiban I, Sangiorgi G: A systematic review and meta-analysis on the hazards of discontinuing or not adhering to aspirin among 50,279 patients at risk for coronary artery disease. Eur Heart J 2006, 27:2667-2674.

65. Di Minno MND, Prisco D, Ruocco AL, Mastronardi P, Massa S, Di Minno G: Perioperative handling of patients on antiplatelet therapy with need for surgery. Intern Emerg Med 2009, 4:279-288.

66. Korte W, Cattaneo M, Chassot P-G, Eichinger S, von Heymann C, Hofmann N, Rickli H, Spannagl M, Ziegler B, Verheugt F, Huber K: Peri-operative management of antiplatelet therapy in patients with coronary artery disease: joint position paper by members of the working group on Perioperative Haemostasis of the Society on Thrombosis and Haemostasis Research (GTH), the working group on Perioperative Coagulation of the Austrian Society for Anesthesiology, Resuscitation and Intensive Care (ÖGARI) and the Working Group Thrombosis of the European Society for Cardiology (ESC). Thromb Haemost 2011, 105:743-749.

67. Di Minno MND, Prisco D, Ruocco AL, Mastronardi P, Massa S, Di Minno G: Perioperative handling of patients on antiplatelet therapy with need for surgery. Intern Emerg Med 2009, 4:279-288.

68. Savonitto S, D'Urbano M, Caracciolo M, Barlocco F, Mariani G, Nichelatti M, Klugmann S, De Servi S: Urgent surgery in patients with a recently implanted coronary drug-eluting stent: a phase II study of "bridging" antiplatelet therapy with tirofiban during temporary withdrawal of clopidogrel. Br J Anaesth 2010, 104:285-291

69. Vicenzi MN, Meislitzer T, Heitzinger B, Halaj M, Fleisher LA, Metzler H: Coronary artery stenting and non-cardiac surgery - a prospective outcome study. Br J Anaesth 2006, 96:686-693.

70. Ferrari E, Benhamou M, Cerboni P, Marcel B: Coronary syndromes following aspirin withdrawal: a special risk for late stent thrombosis. J Am Coll Cardiol 2005, 45:456-459.

doi:10.1186/cc11292

Cite this article as: Beynon C, et al:. Clinical review: Traumatic brain injury in patients receiving antiplatelet medication. Critical Care 2012, 16:228. 